\title{
SH-SY5Y-derived neurons:
}

\section{A human neuronal model system for investigating TAU sort- ing and neuronal subtype-specific TAU vulnerability}

- Review -

Bell, Michael ${ }^{1,2}$, Zempel, Hans ${ }^{1,2}$

1 Institute of Human Genetics, University Hospital Cologne, Kerpener Str. 34, 50931 Cologne, Germany.

${ }^{2}$ Center for Molecular Medicine Cologne (CMMC), Robert-Koch-Str. 21, 50931 Cologne, Germany.

\section{Correspondence}

Michael Bell:

michael.bell@uk-koeln.de

Hans Zempel:

hans.zempel@uk-koeln.de 


\section{Abbreviations}

AD, Alzheimer's Disease; AIS, axon initial segment; BDNF, brain-derived neurotrophic factor; CDC2, cell division cycle kinase 2; CDK5, cyclin-dependent kinase 5; CRISPR/Cas9, clustered regularly interspaced short palindromic repeats/CRISPR-associated protein 9; db-cAMP, dibutyryl-cAMP; EB, end-binding protein; HA tag, human influenza hemagglutinin tag; hiPSC, human-derived induced pluripotent stem cells; LC, locus coeruleus; MAP2, microtubule-associated protein 2; MAPK, mitogen-activated protein kinase; MAPT; microtubule-associated protein TAU-encoding gene; MT, microtubule; $\mathrm{Na}_{\mathrm{v}}$ voltage-gated sodium channel; NB, nucleus basalis, NFT, neurofibrillary tangles; PP1, protein phosphatase 1; PP2A, protein phosphatase 2A; RA, retinoic acid; Ser, Serine; SN, substantia nigra; Thr, Threonine; TRIM46, tripartite motif-containing protein 46, TPA, Phorbol-12-myristate-13-acetate. 


\section{Abstract}

The microtubule-associated protein TAU is sorted into the axon in healthy brain neurons. Somatodendritic missorting of TAU is a pathological hallmark of many neurodegenerative diseases called tauopathies, including Alzheimer's Disease (AD). Cause, consequence, and (patho)physiological mechanisms of TAU sorting and missorting are understudied, in part also due to the lack of readily available human neuronal model systems. The human neuroblastoma cell line SH-SY5Y is widely used for studying TAU physiology and TAUrelated pathology in AD and related tauopathies. SH-SY5Y cells can be differentiated into neuron-like cells (SH-SY5Y-derived neurons) using various substances. This review evaluates whether SH-SY5Y-derived neurons are a suitable model for i) investigating intracelIular TAU sorting in general, and ii) with respect to neuron subtype-specific TAU vulnerability. I) SH-SY5Y-derived neurons show pronounced axodendritic polarity, high levels of axonally localized TAU protein, expression of all six major human brain isoforms, and TAU phosphorylation similar to the human brain. As proliferative cells, SH-SY5Y cells are readily accessible for genetic engineering, stable transgene integration and leading-edge genome editing are valuable and promising tools for TAU-related studies. II) Depending on the used differentiation procedure, SH-SY5Y-derived neurons resemble cells of distinct subcortical nuclei, i.e. the Locus coeruleus (LC), Nucleus basalis (NB) and Substantia nigra (SN), all of which early affected in many tauopathies. This allows to analyse neuronspecific TAU isoform expression and intracellular localization, also in the context of vulnerability to TAU pathology. Limitations are e.g. the lack of mimicking age-related tauopathy risk factors and the difficulty to define the exact neuronal subtype of SH-SY5Y-derived neurons. In brief, this review discusses the suitability of SH-SY5Y-derived neurons for investigating TAU (mis)sorting mechanisms and neuron-specific TAU vulnerability in disease paradigms.

Key words: SH-SY5Y-derived neurons, TAU sorting, neuronal identity, tauopathy, Alzheimer's disease 


\section{Table of Contents}

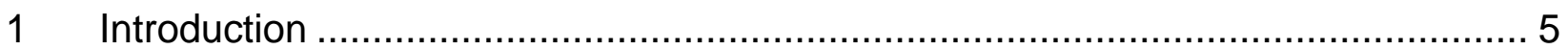

2 Suitability of SH-SY5Y-derived neurons for investigating TAU sorting .................. 7

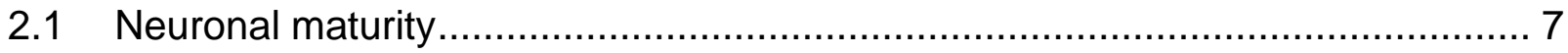

2.2 TAU expression \& subcellular localization .................................................. 8

2.3 Expression pattern of TAU isoforms …….............................................. 10

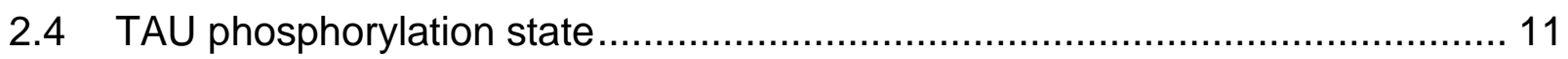

2.5 Genetic engineering of SH-SY5Y cells …............................................. 12

3 Neuronal identity of SH-SY5Y-derived neurons ............................................... 15

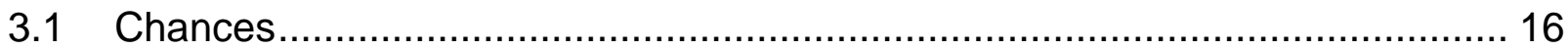

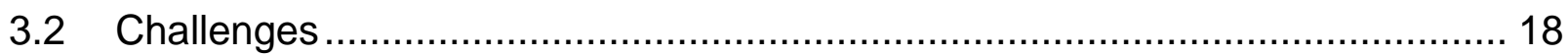

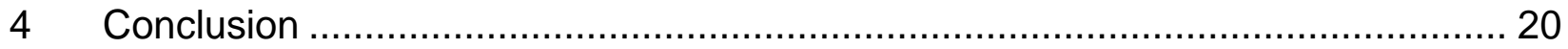

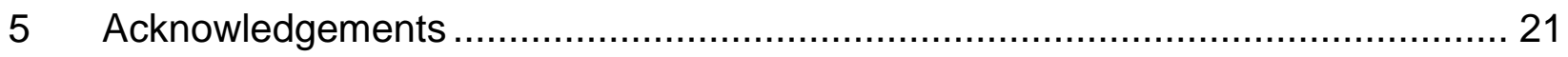

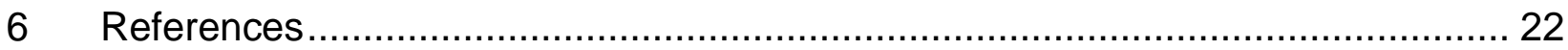




\section{Introduction}

Alzheimer's disease $(A D)$ and related neurodegenerative diseases constitute a major scourge of modern healthcare due to their tremendously high and increasing prevalence 1. One key player in $A D$ and related so-called tauopathies is the microtubule-associated protein TAU. Under healthy conditions, TAU is sorted to the axonal compartment of brain neurons ${ }^{2,3}$ where it regulates the assembly of microtubule filaments ${ }^{4,5}$. TAU missorting into the somatodendritic compartment, site-specific hyperphosphorylation and formation of TAU-containing neurofibrillary tangles (NFT) are typical pathological hallmarks of $A D$ and other tauopathies ${ }^{6-8}$. In the last decades, much effort has been invested in unravelling the physiological functions and pathomechanisms linked to TAU sorting and missorting.

Mouse models or rodent-derived neuronal cultures are commonly used for TAU studies in general, including research on TAU sorting. However, these models have several limitations as i) they require the sacrification of animals, ii) they suffer from limitations in translatability, including different isoform expression patterns and species-dependent differences regarding the cellular machinery and interaction partners ${ }^{9}$, and iii) in case of 'humanized' mouse models, they exhibit artificial genetic settings due to overexpression of (multiple) human transgenes ${ }^{10-13}$ (see Table 1 for summary. Another cellular model, human induced pluripotent stem cell (hiPSC)-derived neurons overcome many of these obstacles and constitute a powerful tool for TAU-related research ${ }^{14-18}$. However, differentiation of hiPSC-derived neurons is expensive, time-consuming and results in cultures with variable homogeneity and differentiation efficiency ${ }^{19-21}$ (see Table 1 for summary).

The human neuroblastoma cell line SH-SY5Y, subcloned from the SK-N-SH line ${ }^{22}$, is an easy-to-handle and proliferative cell line with well-established differentiation methods for generating stable neuronal cultures (see chapters $2.1 \& 3$ ). SH-SY5Y-derived neurons have been widely used for TAU-related research, as they yield homogeneous, reproducible human-derived neuronal cultures with robust expression and axonal distribution of TAU, thereby suitable also for addressing axonal TAU sorting ${ }^{23}$ (see Table 1 for summary). Interestingly, the neuronal identity of SH-SY5Y-derived neurons depends on the 
used differentiation procedure ${ }^{23}$, which bears potential for neuronal subtype-specific TAU studies.

The current review aims to evaluate the suitability of SH-SY5Y-derived neurons for TAU sorting research. Moreover, the chances and challenges of the drug-dependent identity of SH-SY5Y-derived neurons will be discussed regarding their utility to mimic neuronal subtypes of brain regions that are early affected in $A D$ and other tauopathies. 


\section{Suitability of SH-SY5Y-derived neurons for investigating TAU sorting}

\subsection{Neuronal maturity}

Neuronal maturity is an important prerequisite for TAU sorting-related research as TAU is specifically enriched in the axon of mature neurons ${ }^{2,3}$. The human SH-SY5Y neuroblastoma cells can be differentiated into neuronal cells with several substances, including the vitamin A derivative retinoic acid (RA), different phorbol esters, dibutyryl-cAMP, or the brain-derived neurotrophic factor (BDNF) ${ }^{23}$. The maturation of SH-SY5Y-derived neurons is well characterized, especially for RA- and BDNF-based differentiation.

There are observations that question the neuronal maturity of SH-SY5Y-derived neurons, such as the moderate outgrowth of dendritic processes ${ }^{24,25}$ or the lack of spontaneous activity after RA-driven differentiation ${ }^{26}$. Jahn and colleagues (2017) argue, however, that spontaneous activity, seen e.g. in rodent primary cultures, might not be mandatory to prove neuronal maturity. Further, Ankyrin G (ANKG) is weakly expressed in SH-SY5Yderived neurons without enrichment at the proximal axon ${ }^{25}$. ANKG is known to be a key player for the development of the axon initial segment (AIS), a specialized region at the proximal axon, involved in the generation of action potentials and anterograde cargo transport 27,28 .

On the other hand, SH-SY5Y-derived neurons express classical neuronal maturation markers as neuronal nuclei (NeuN), high-weight neurofilament (NF-H), the microtubuleassociated protein 2 (MAP2), or growth-associated protein 43 (GAP43) 24-26,29-36. They are excitable due to the expression of voltage-gated sodium (e.g. Nav1.1, Nav1.2), calcium and potassium channels ${ }^{37-41}$, and they exhibit activity-dependent synapse and vesicle formation ${ }^{26,32,42}$, suggesting the presence of functional synaptic networks. Morphologically, SH-SY5Y-derived neurons exhibit pronounced axonal outgrowth (Fig. 1A) 23-25,36. Taken together, there is strong evidence for the neuronal maturity and function of $\mathrm{SH}$ SY5Y-derived neurons. 


\subsection{TAU expression \& subcellular localization}

Little amounts of TAU protein are detectable in undifferentiated SH-SY5Y cells, where it is present in the cytoplasm and in the nucleus ${ }^{43}$. Differentiation of SH-SY5Y cells with RA or the phorbol ester TPA results in a strong increase of overall TAU protein levels ${ }^{24,44}$ with a neuron-like subcellular distribution, i.e. increased axonal and decreased somatic TAU levels (Fig. 1A,B) ${ }^{24,33,43}$. The use of combinatorial treatments, e.g. RA and BDNF or BDNF and the neuronal growth factor (NGF), further enhances the axonal outgrowth and the total TAU expression to levels ${ }^{24,25,33,36}$, comparable to those of the human brain ${ }^{33}$. The observed separation of axonal TAU and somatodendritic microtubule-associated protein 2 (MAP2) (Fig. 1B) 24,25,36 indicates the neuronal polarity 45 .

In this context, it would be worth to examine whether SH-SY5Y-derived neurons properly distribute also transfected TAU, an often-faced challenge in experiments with rodent primary cultures ${ }^{25,46,47}$. Indeed, recent data suggest that SH-SY5Y-derived neurons tolerate overexpression of transfected HA-tagged TAU better than primary cultures (at least nine days), and that they sort transfected TAU with endogenous-like efficiency ${ }^{25}$ (see Table 1 for comparison). It is remarkable that efficient sorting of endogenous and transfected TAU obviously happens without classical ANKG-mediated AIS formation in SH-SY5Y-derived neurons ${ }^{25}$. Former studies claimed that ANKG-mediated AIS formation is critical for the process of neuronal polarization ${ }^{27,28,48}$, while more recent studies, indeed, question the necessity of ANKG for proper TAU sorting ${ }^{49,50}$. More studies are necessary to clarify the role of ANKG and other AIS proteins, e.g. the tripartite motif-containing protein 46 (TRIM46) or end-binding proteins (EBs), in the context of axonal TAU sorting. 

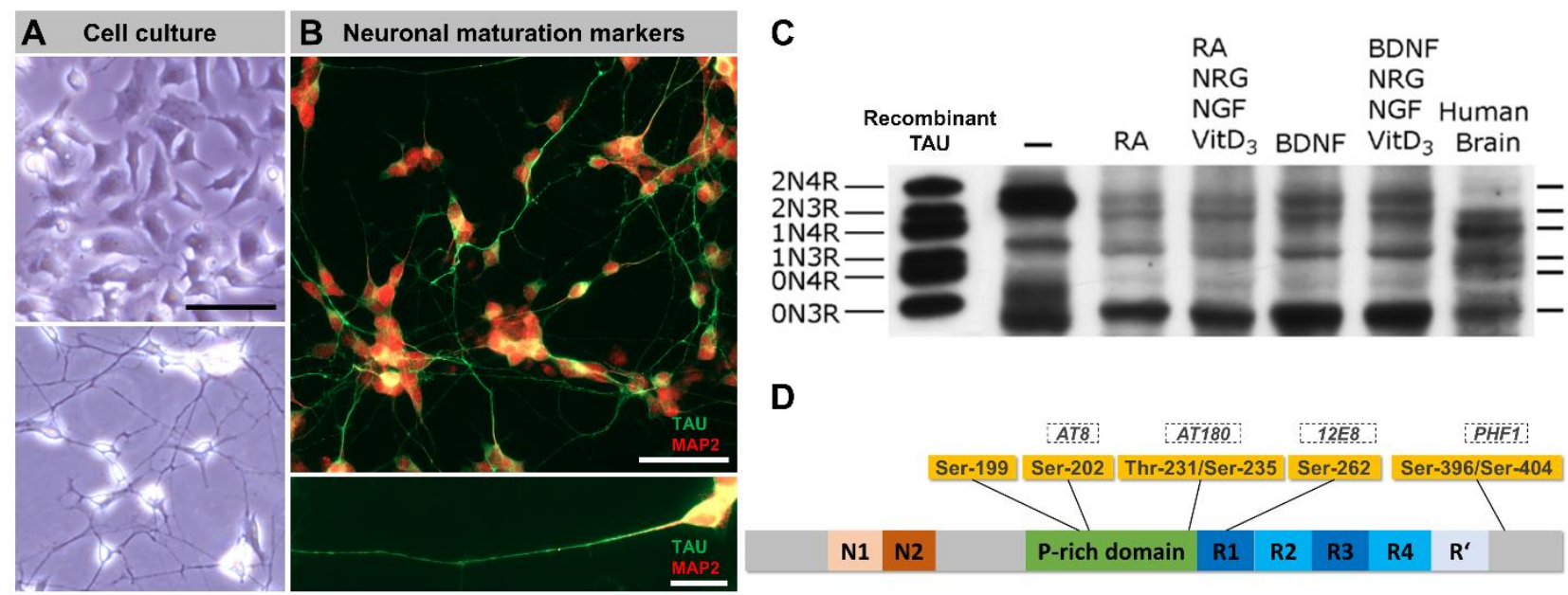

Figure 1: Suitability of SH-SY5Y-derived neurons for TAU sorting research. A) Representative images of undifferentiated SH-SY5Y cells (left, top panel) and SH-SY5Y-derived neurons (left, bottom) in culture (cultures were grown on Poly-D-Lysine $(20 \mu \mathrm{g} / \mathrm{ml})$-coated glass coverslips in DMEM/F12 (\#10565018, TFS) and $10 \%$ fetal bovine serum (BioChrom AG); for differentiation, cells were grown for 7 days in DMEM/F12, $10 \%$ fetal bovine serum and $10 \mu \mathrm{M}$ retinoic acid (RA), followed by 7 days in serum-free DMEM/F12 and 10 $\mathrm{ng} / \mathrm{ml}$ brain-derived neurotrophic factor (BDNF). Note the altered morphology and pronounced neurite outgrowth upon differentiation. Scale bar: $50 \mu \mathrm{m}$. B) Immunostainings of SH-SY5Y-derived neurons (cells were fixed with $3.7 \%$ FA for $1 \mathrm{~h}$, blocked with $5 \%$ BSA and $0.1 \%$ Triton X-100 for 5 minutes, immunostained with polyclonal anti-TAU (K9JA, 1:1000 in PBS, A0024, DAKO, $2^{\text {nd }}$ AB: donkey anti-rabbit + AlexaFluor488, 1:1000 in PBS, A21202, TFS) and chicken anti-MAP2 (1:2000, ab5392, Abcam, ${ }^{\text {nd }} A B$ : goat anti-chicken AF647, 1:1000 in PBS, A21449, TFS) antibodies, and mounted (PolyMount, Polysciences), procedure adapted from ${ }^{92}$ ) demonstrate the strong expression and polarized distribution of neuronal maturation markers TAU (green, mainly axonal) and MAP2 (red, mainly somatic). Scale bar (top): $50 \mu \mathrm{m}$, scale bar (bottom): $20 \mu \mathrm{m}$. C) Western blot analysis of TAU isoform expression (de-phosphorylated lysates) in undifferentiated SH-SY5Y cells (lane 1), differently treated SH-SY5Y-derived neurons (lanes $2-5$ ) and human brain lysate (lane 6). The very left lane shows a recombinant TAU standard. Note the abundance of all six isoforms upon differentiation with varying ratios compared to the human brain. The blot was adapted and modified from ${ }^{33}$. D) Overview of the TAU protein (grey bar, colored sections indicate distinct TAU domains) and common tauopathy-associated TAU hyperphosphorylation sites (yellow boxes, corresponding epitopes that are recognized by specific antibodies are indicated dashed boxes) that appear highly phosphorylated in SH-SY5Y cells. 


\subsection{Expression pattern of TAU isoforms}

Alternative splicing of the exons 2 and 3 (either $0 \mathrm{~N}, 1 \mathrm{~N}$, or $2 \mathrm{~N}$ isoforms) as well as exon 10 (3R or 4R isoforms) results in six major TAU isoforms in the mature human brain 4,51,52, compared to only three isoforms in the adult rodent brain ${ }^{53}$. It is thus clear that a suitable model for studying TAU sorting should be human-derived and display the expression of all human TAU isoforms. The isoform expression pattern in the human brain was depends on the developmental stage and the analysed brain region ${ }^{51,54-56}$. Moreover, the axodendritic distribution is markedly different between the six major TAU isoforms ${ }^{57}$.

Early studies on TAU isoform expression in SH-SY5Y cells showed consistently that undifferentiated cells express only the shortest TAU isoform 0N3R 43,44,58,59. More recently, TAU mRNA containing exon $2(1 \mathrm{~N})$ or exon $10(4 \mathrm{R})$ was found in untreated SH-SY5Y cells, suggesting at least basal expression of larger isoforms (Fig. 1C) ${ }^{33}$. Reports about differentiated SH-SY5Y-derived neurons vary in their described isoform expression pattern. Former studies detected either no shift in isoform expression upon RA treatment ${ }^{44}$, weak expression of an additional $64 \mathrm{kDa}$-sized isoform (probably representing the 2N4R isoform) ${ }^{58}$, or low levels of $4 R$ isoform mRNA upon three weeks of RA treatment ${ }^{43}$. More recent findings, however, showed that undifferentiated SH-SY5Y cells already express high amounts of $1 \mathrm{~N}$ isoforms, and that differentiated cells express all six major isoforms (Fig. 1C) ${ }^{33}$.

The isoform ratio in SH-SY5Y-derived neurons differs notably from the human brain ${ }^{60}$, with more $3 R$ than $4 R$ TAU, less $2 \mathrm{~N}$ isoforms and more $0 N 3 R-T A U{ }^{33}$. This may suggest that a cultivation time of up to three weeks produces $\mathrm{SH}-\mathrm{SY} 5 \mathrm{Y}$-derived neurons at an intermediate stage of maturity. Later studies, however, found roughly equal amounts of $3 R$ and $4 R$ isoforms, as typically seen in the adult human brain ${ }^{61-64}$, after RA treatment 65. Despite this discrepancy regarding the isoform ratio, these studies demonstrate the principal presence of all six TAU isoforms in SH-SY5Y-derived neurons. 
$A D$ animal models, which express all six human TAU isoforms while the endogenous mouse Mapt expression is knocked out ${ }^{12,13}$, have already been available for years. However, one bottleneck for these AD animal models is to achieve a human-like isoform ratio of $3 R$ and $4 R$ isoforms. Recent mouse lines could overcome this issue by introducing multiple, partially mutagenized human MAPT transgenes into a Mapt-KO mouse background ${ }^{10,11}$. However, these mice harbour a highly artificial genetic MAPT setup, and they still lack a human cellular environment, making e.g. isoform-specific interaction studies difficult to interpret.

SH-SY5Y-derived neurons can serve to clarify whether certain TAU isoforms contribute differently to cellular TAU functions under physiological conditions and possibly convey tauopathy-related toxicity, e.g. by being more susceptible to mislocalization, hyperphosphorylation or aggregation. Taken together, the TAU isoform ratio of $\mathrm{SH}-\mathrm{SY} 5 \mathrm{Y}$-derived neurons differs from that in the mature human brain, but the strong expression of all six major isoforms already upon brief differentiation periods allows investigating TAU isoformspecific localization and disease-associated mislocalization.

\subsection{TAU phosphorylation state}

More than 90 reported phosphorylation sites illustrate the striking importance of these posttranslational modifications for TAU functionality ${ }^{64}$. The phosphorylation state of TAU directly influences the microtubule-binding affinity and thereby its mobility and intracellular localization ${ }^{66-70}$. Hyperphosphorylation correlates with somatodendritic missorting and aggregation of TAU ${ }^{70-76}$.

Consequently, early TAU studies with SH-SY5Y cells put great effort into analysing the phosphorylation state of TAU in SH-SY5Y cells. They revealed that many TAU residues, including Ser-199, Ser-202 (AT8 epitope), Thr-231/Ser-235 (AT180 epitope), Ser-262 (12E8 epitope) and Ser-396/Ser-404 (PHF1 epitope) are phosphorylated in undifferentiated SH-SY5Y cells (Fig. 1D) ${ }^{44,59,77}$. As many of these residues are hyperphosphorylated also in AD, TAU was considered as phosphorylated in an AD-like manner ${ }^{59}$. The phosphorylation state can be explained by the high levels of ON3R-TAU in undifferentiated SH- 
SY5Y cells. In early developmental stages, when 0N3R-TAU is the predominant isoform, TAU phosphorylation is increased ${ }^{51,75}$. Interestingly, no substantial change in TAU phosphorylation was seen upon differentiation with RA ${ }^{44}$ despite the expression of larger TAU isoforms ${ }^{33,65}$. This might be due to the fact that 0N3R-TAU appears as the major isoform also in differentiating SH-SY5Y cells ${ }^{33}$.

It was first shown in SH-SY5Y cells that okadaic acid and other phosphatase inhibitors can evoke AD-like TAU hyperphosphorylation, MT disassembly and cell death, by inactivating PP1 and PP2A phosphatases and activating MAPK, CDC2 and CDK5 kinases $58,78,79$. These findings in SH-SY5Y cells provided a direct link between phosphorylation state, MT stability and cell death, as it was postulated from previous in vitro interaction assays ${ }^{64}$. Many recent TAU studies in SH-SY5Y cells focused on TAU(hyper)phosphorylation, including the role of kinases/phosphatases and cellular pathways in misbalancing the TAU phosphorylation state ${ }^{77,80-83}$, the influence of microglia-mediated neuroinflammation ${ }^{65,84-86}$, the link between hyperglycaemia and TAU phosphorylation ${ }^{87-90}$, or the correlation of TAU phosphorylation and sleep disorders in AD patients ${ }^{91}$.

Taken together, the TAU phosphorylation state in SH-SY5Y cells is similar to that of human brain neurons ${ }^{59,64}$, and its regulation involves known TAU-interacting kinases and phosphatases ${ }^{78,80,81}$. These great similarities in TAU phosphorylation are critical for the suitability of SH-SY5Y derived neurons for the investigation of TAU sorting since TAU phosphorylation and (mis)sorting are closely linked.

\subsection{Genetic engineering of SH-SY5Y cells}

SH-SY5Y-derived neurons display many features of matured neuronal cells, including the post-mitotic character. Post-mitotic cells are inaccessible for most stable genetic engineering approaches. However, in the undifferentiated state, SH-SY5Y cells are rapidly dividing and can be used for the stable integration of transgenes, including variants of the TAU-encoding MAPT gene. In the past, transfection and stable integration of linearized 1N3R- and 1N4R-MAPT CDNA into SH-SY5Y cells was used to mimic the misbalance of 
$3 \mathrm{R} / 4 \mathrm{R}$ isoform ratios ${ }^{93,94}$, which is caused by MAPT variants that affect alternative splicing in several tauopathies ${ }^{95}$.

Other studies generated SH-SY5Y cell lines with stable overexpression of only 4R isoforms ${ }^{96}$, a exon 6 containing isoform ${ }^{97}$ or a pro-aggregant TAU variant ${ }^{86,98}$. These transgenic TAU isoforms or mutants are, however, lacking the features of endogenous MAPT expression regulation. The application of recent genome editing techniques, such as CRISPR/Cas9, was shown to work in SH-SY5Y cells ${ }^{99-103}$. This allows the generation of complete or isoform-specific TAU knock-out lines or the introduction of gene edits on a single base level, e.g. by using base editor enzymes ${ }^{104}$ or the recently described prime editing technique ${ }^{105}$.

However, one has to consider the genetic predispositions of SH-SY5Y cells, as largescale chromosomal abnormalities and imbalances are reported for neuroblastoma cell lines in general ${ }^{106-110 . ~ A c c o r d i n g l y, ~ S H-S Y 5 Y ~ c e l l s ~ s h o w ~ t r i s o m y ~ o f ~ c h r o m o s o m e ~(c h r) ~} 7$, a duplication of the q-arm of chr1, and further complex rearrangements on the majority of chromosomes leading to both copy number gains and losses ${ }^{111}$. Besides other loci of neurobiological interest, a copy number gain of the MAPT locus on chr17 was confirmed in different studies ${ }^{111-115}$. This genetic arrangement of SH-SY5Y cells complicates the generation of homozygous MAPT mutant knock-out (KO) or knock-in cell lines, as it requires successful editing of presumably three MAPT gene copies, and also impedes heterozygous edits, which usually lead to roughly $50 \%$ of affected proteins. The successful generation of a MAPT-KO SH-SY5Y cell line recently demonstrated that in fact CRISPR/Cas9-based homozygous MAPT editing is possible in SH-SY5Y cells ${ }^{116}$. 
Table 1: Comparison of neuronal model systems for TAU sorting research.

\begin{tabular}{|c|c|c|c|c|}
\hline Feature & $\begin{array}{l}\text { SH-SY5Y- } \\
\text { derived } \\
\text { neurons }\end{array}$ & $\begin{array}{l}\text { Rodent } \\
\text { primary } \\
\text { neurons }\end{array}$ & $\begin{array}{c}\text { 'Humanized' } \\
\text { mouse } \\
\text { models } \\
\end{array}$ & $\begin{array}{l}\text { hiPSC- } \\
\text { derived } \\
\text { neurons }\end{array}$ \\
\hline Human-derived & + & - & - & + \\
\hline No animal need & + & - & - & + \\
\hline Proliferative & + & - & - & + \\
\hline Low cultivation cost & + & $(+)$ & - & - \\
\hline $\begin{array}{c}\text { Accessible for } \\
\text { genetic manipulation }\end{array}$ & + & $(+)$ & + & + \\
\hline Fast differentiation & + & + & - & $(+)$ \\
\hline Culture homogeneity & $(+)$ & $(+)$ & + & $(+)$ \\
\hline Neuronal maturity & $(+)$ & + & + & $(+)$ \\
\hline $\begin{array}{l}\text { Expression of six } \\
\text { TAU isoforms }\end{array}$ & + & - & $(+)$ & + \\
\hline $\begin{array}{c}\text { Human brain-like } \\
\text { Phosphorylation state }\end{array}$ & + & n/a & + & n/a \\
\hline $\begin{array}{l}\text { Efficient sorting of } \\
\text { endogenous TAU }\end{array}$ & + & + & + & + \\
\hline $\begin{array}{l}\text { Efficient sorting of } \\
\text { transfected TAU }\end{array}$ & + & - & n/a & n/a \\
\hline \multicolumn{5}{|c|}{$\begin{array}{l}+=\text { feature is present/available in this cell model, } \\
(+)=\text { feature is partially present/available or dependent on the experimental (e.g. cultivation, differentia- } \\
\text { tion, (trans)genetic setup) conditions } \\
-=\text { feature is not or almost not present/available for this model, } \\
n / a=\text { no data available }\end{array}$} \\
\hline
\end{tabular}




\section{Neuronal identity of SH-SY5Y-derived neurons}

The susceptibility to TAU pathology varies drastically among different brain regions, neuronal subtypes and depending on the type of disease ${ }^{117-119}$, as well as TAU expression levels, the subcellular TAU distribution, or the TAU isoform ratio ${ }^{54}$. This raises the question whether TAU properties per se are crucial for the different susceptibility of different brain regions being affected by TAU pathology and TAU-mediated neurodegeneration. Thus, a cell model that mimics features of early affected brain regions would bear great potential for future research.

Undifferentiated SH-SY5Y cells are considered immature catecholaminergic neurons since they express markers of immature neurons ${ }^{34,35}$ and key proteins of the catecholaminergic metabolism $23,34,35,120,121$. Interestingly, the reports about the neuronal identity of mature SH-SY5Y-derived neurons vary depending on the substances used for differentiation protocols ${ }^{23}$ (see Fig. 2 for summary). The most common and often-used substance, the vitamin A derivative retinoic acid (RA), was shown to elevate the levels of activated choline acetyltransferase, which is typical for cholinergic neurons ${ }^{34,122,123}$. However, the cholinergic character of RA-treated cells is under debate, as the expression of noradrenaline ${ }^{30}$ and of the vesicular monoamine transporter, a key enzyme of catecholaminergic neurons, was reported in some studies ${ }^{34,122}$, but not in others ${ }^{24}$. Another common differentiation procedure, the combinatorial treatment of RA and the brain-derived neurotrophic factor (BDNF) results in extensively branched neurons, which are categorized based on the expression of marker proteins either as noradrenergic ${ }^{24}$, dopaminergic ${ }^{124}$ or cholinergic ${ }^{125}$. Besides RA and BDNF, phorbol esters (e.g. Phorbol-12-myristate-13-acetate (TPA) ${ }^{30,126-128}$, dibutyryl-cAMP (db-cAMP) ${ }^{129-131}$ or other drugs are used alone or in combination ${ }^{30,132}$ to generate SH-SY5Y-derived neurons with varying neuronal identity, e.g. noradrenergic (TPA, db-cAMP) or dopaminergic (RA+TPA).

Taken together, the classification of SH-SY5Y-derived neurons may depend on the applied substances and be influenced by the focuses of the actual study. It is, however, 
certain that SH-SY5Y-derived neurons display some key features of noradrenergic, dopaminergic, and cholinergic neurons. This gives rise to both i) the potential of SH-SY5Yderived neurons for studies on neuronal subtype-specific $A D /$ tauopathy susceptibility and ii) the accompanying challenges, including the resemblance of age-related risk factors, as summarized and discussed below (see Table 2 for summary).

\subsection{Chances}

In the progression of $A D$ and other neurodegenerative diseases, certain brain regions are typically early affected while other regions show pathological alterations only in late disease stages. In several subcortical nuclei, considerable neuronal loss can be observed in initial disease stages or even pre-clinically ${ }^{64}$. These subcortical nuclei are, amongst others, the Nucleus basalis (NB, containing mainly cholinergic neurons), the Substantia nigra (SN, dopaminergic neurons) and the Locus coeruleus (LC, noradrenergic neurons) ${ }^{133}$. The formation of TAU-containing NFT's in NB neurons and massive depletion of acetylcholine within cortical and hippocampal regions, resulting from a loss of NB cholinergic projections, coincide with early clinical symptoms of AD ${ }^{133-139}$. Within the SN, TAU-NFT formation, pigmented neuronal loss and other pathological alterations are found in $A D{ }^{140-}$ 145 and other tauopathies ${ }^{146,147}$. Also the noradrenergic neurons of the LC complex are early affected by NFT formation and degeneration in AD patients ${ }^{148-153}$, and seem to become compromised even in young adults without any clinical phenotype ${ }^{118}$.

While comprehensive descriptions of TAU-NFT formation and neuronal loss in these subcortical nuclei are available, the pathomechanisms underlying their vulnerability are still elusive ${ }^{154}$. Since SH-SY5Y-derived neurons share properties of LC, NB, or SN neurons (see chapter 3 ), they may be a powerful tool for the evaluation of subtype-dependent vulnerability. This is particularly true as the TAU physiology specific for these neurons may contribute to their increased vulnerability. Several aspects mimicking neuronal TAU physiology are available in SH-SH5Y-derived neurons: subcellular distribution, phosphorylation state, isoform expression levels and ratios, isoform-specific intracellular localization 
of TAU and cell-stress induced development of NFT formation or, at least, NFT-like hyperphosphorylation (see chapter $2.1 \mathrm{ff}$ ).

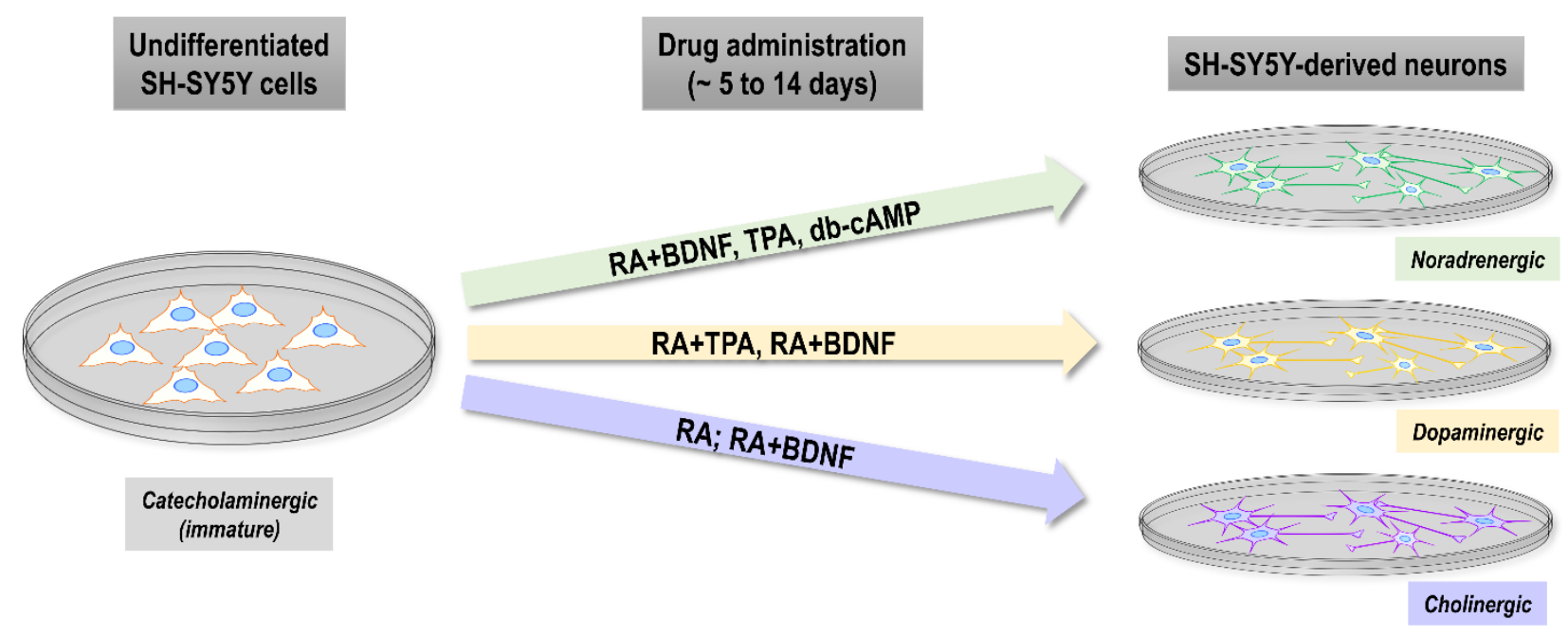

Figure 2: Treatment-dependent neuronal identity of SH-SY5Y-derived neurons. Overview of the reported neuronal identity for undifferentiated SH-SY5Y cells (left) and SH-SY5Y-derived neurons (right) with respect to commonly administered substances (middle) for differentiation. Undifferentiated SH-SY5Y display features of immature catecholaminergic neurons. Primarily noradrenergic neurons are reported after treatment with RA and BDNF, TPA or db-cAMP, primarily dopaminergic neurons after treatment with RA and TPA or RA and BDNF. Neurons with a cholinergic identity result from differentiation with RA or with RA and BDNF. Administration with two drugs always refers to sequential treatment in the order of appearance. Duration of drug administration varies between protocols but is usually between 5 and 14 days. 


\subsection{Challenges}

Besides the advantages of SH-SY5Y-derived neurons for studying neuron subtype-specific TAU vulnerability, there are also limitations that has to be considered. As for all cellular models of $A D$ or related tauopathies, which are largely ageing-dependent disorders ${ }^{155-158}$, it is questionable whether up to three-week-old neuronal cultures can resemble the cellular properties of subcortical neurons in the brain of aged AD patients. Furthermore, the expression profiles, e.g. of RA- and RA/BDNF-treated cells, appear inconsistent among different studies, and it remains questionable whether the neuronal subtype can be clearly defined. Especially, this is a non-negligible issue since a more comprehensive biochemical characterization of the generated neurons would be expensive and time-consuming, without the guarantee of a conclusive outcome. Indeed, the available data rather suggest that $\mathrm{SH}$-SY5Y-derived neurons do not resemble clearly segregated and distinct neuronal subtypes, which can be separated by protein expression or transmitter release, but rather exhibit different manifestations of a gradual neuronal entity.

Another obstacle of using SH-SY5Y-derived neurons may be that major features of LC, NB and SN neurons are difficult to recapitulate in cell culture, which is in fact a general problem for transferring findings from cell cultures to brain/living organisms. However, these features of subcortical neurons, which are hard to display in vitro, might have massive impact on the vulnerability of those neurons. Specific features of LC neurons ${ }^{154}$ include i) the up to several $\mathrm{cm}$-long, thin and poorly myelinated, heavily branched axons spanning throughout the cortex without relay, which leads to high energy demand and oxidative stress ${ }^{159-161}$ (SH-SY5Y-derived neurons: axons range roughly between 50-150 $\mu \mathrm{m}$ for RA, TPA or db-cAMP treatment ${ }^{122,126,129,132}$ and up $200 \mu \mathrm{m}$ and more for RA/BDNF ${ }^{24,36}$, and show only moderate branching), ii) increased energy demand and ROS production due to the tonic activity ${ }^{162}$ (SH-SY5Y-derived neurons: increased excitability and membrane potentials ${ }^{38,163,164}$ but no tonic activity) and iii) elevated exposure to toxins and pathogens as LC neurons innervate the CNS capillary system and associated astrocyte end feet ${ }^{165-167}$. As all subcortical nuclei share great similarities regarding morphology and innervation ${ }^{168,169}$, the mentioned risk factors may be largely true for NB and SN neurons, 
as well ${ }^{159,160}$, probably contributing to their susceptibility for early TAU pathology in disease.

In brief, the targeted differentiation of SH-SY5Y cells into neurons with features of noradrenergic, dopaminergic, or cholinergic neurons bears great potential for research on $A D$ selective vulnerability since the mimicked subcortical nuclei are early affected in AD patients. However, the generation of distinct neuronal subtypes does not appear clearly defined with current differentiation procedures, and SH-SY5Y-derived neurons lack major characteristics of their in vivo correlates, that might be crucial for tauopathy-related vulnerability.

Table 2: Chances and challenges of the neuronal identity of SH-SY5Y-derived neurons

\section{Chances}

+ Targeted neuronal differentiation with straight-forward protocols

+ Features of subcortical nuclei early affected in tauopathies

+ Locus coeruleus (LC, mainly noradrenergic)

+ Substantia nigra (SN, mainly dopaminergic)

+ Nucleus basalis (NB, mainly cholinergic)

+ Comparative studies on neuronal subtype-specific TAU vulnerability

\section{Challenges}

- Lack of age-related tauopathy risk factors

- Inconclusive reports about neuronal identity upon differentiation

- $\quad$ Lack of major features of LC, SN and NB subcortical neurons

- Up to cm-long, thin axons spanning across the cortex without relay

- Tonic activity with high energy demand and oxidative stress

- Innervation of the capillary system (exposure to toxins \& pathogens) 


\section{Conclusion}

Human-derived SH-SY5Y neuroblastoma cells are robust, cheap, highly proliferative, and can be differentiated into neuronal cells with straightforward protocols. Although the maturity of SH-SY5Y-derived neurons is under debate, they meet several requirements for TAU sorting research: $\mathrm{SH}-\mathrm{SY} 5 \mathrm{Y}$-derived neurons exhibit i) pronounced neuronal polarity after several days of differentiation, ii) high levels of total TAU protein, iii) expression of all major human isoforms, iv) efficient axonal targeting of TAU protein, and v) an human brain-like TAU phosphorylation state. Further, SH-SY5Y cells are accessible for genetic manipulation, i.e. stable integration of recombinant TAU transgenes and editing of the MAPT locus by means of recent CRISPR/Cas9-based methods prior to neuronal differentiation.

SH-SY5Y-derived neurons resemble, depending on the used treatment, neuron subtypes of distinct subcortical LC, NB and SN nuclei that are severely affected in AD and other tauopathies. This steerable differentiation bears great potential for comparative studies of neuron-specific TAU expression patterns, intracellular localization, and vulnerability to TAU pathology. However, there are inherent limitations regarding the translatability from $\mathrm{SH}-\mathrm{SY} 5 Y$-derived to subcortical neurons, e.g. the lack of age-dependent risk factors, the difficulty of defining the exact neuronal subtype or the lack of brain-spanning projections (on a cm-scale) leading to high energy demands and oxidative stress. These caveats have to be considered when addressing cell type-specific vulnerability in SH-SY5Y-derived neurons.

All in all, the properties of SH-SY5Y-derived neurons discussed in this review make them a powerful neuronal cell model for investigating the mechanisms of and requirements for axonal TAU sorting under human-like conditions. 


\section{Acknowledgements}

We thank Sarah Bachmann and others for critical manuscript revision. This work was funded by Else-Kröner-Fresenius Stiftung, Köln Fortune, and supported by a doctoral fellowship of the Studienstiftung des deutschen Volkes. The authors declare that they have no competing interests. 


\section{References}

1. Korolev, I. O. Alzheimer 's Disease : A Clinical and Basic Science Review. Med. Student Res. J. (2014).

2. Binder, L. I., Frankfurter, A. \& Rebhun, L. I. The distribution of tau in the mammalian central nervous central nervous. J. Cell Biol. (1985). doi:10.1083/jcb.101.4.1371

3. Kempf, M., Clement, A., Faissner, A., Lee, G. \& Brandt, R. Tau binds to the distal axon early in development of polarity in a microtubule- and microfilamentdependent manner. J. Neurosci. (1996).

4. Cleveland, D. W., Hwo, S. Y. \& Kirschner, M. W. Physical and chemical properties of purified tau factor and the role of tau in microtubule assembly. J. Mol. Biol. (1977). doi:10.1016/0022-2836(77)90214-5

5. Weingarten, M. D., Lockwood, A. H., Hwo, S. Y. \& Kirschner, M. W. A protein factor essential for microtubule assembly. Proc. Natl. Acad. Sci. U. S. A. (1975). doi:10.1073/pnas.72.5.1858

6. Wischik, C. M. et al. Isolation of a fragment of tau derived from the core of the paired helical filament of Alzheimer disease. Proc. Natl. Acad. Sci. U. S. A. (1988). doi:10.1073/pnas.85.12.4506

7. Brion, J. P., Passareiro, H., Nunez, J. \& Flament-Durand, J. Mise en Evidence Immunologique de la Proteine Tau au Niveau des Lesiones de Degenerescence Neurofibrillaire de la Maladie d'Alzheimer. Arch. Biol. (Liege). (1985).

8. Zempel, H. \& Mandelkow, E. Lost after translation: Missorting of Tau protein and consequences for Alzheimer disease. Trends in Neurosciences (2014). doi:10.1016/j.tins.2014.08.004

9. Janke, C. et al. Phylogenetic diversity of the expression of the microtubuleassociated protein tau: Implications for neurodegenerative disorders. Mol. Brain Res. (1999). doi:10.1016/S0169-328X(99)00079-0

10. He, Z. et al. Transmission of tauopathy strains is independent of their isoform composition. Nat. Commun. (2020). doi:10.1038/s41467-019-13787-x

11. Hashimoto, $\mathrm{S}$. et al. Tau binding protein CAPON induces tau aggregation and neurodegeneration. Nat. Commun. (2019). doi:10.1038/s41467-019-10278-x

12. Andorfer, C. et al. Hyperphosphorylation and aggregation of tau in mice expressing normal human tau isoforms. J. Neurochem. (2003). doi:10.1046/j.1471-4159.2003.01879.x

13. Duff, K. et al. Characterization of pathology in transgenic mice over-expressing human genomic and cDNA tau transgenes. Neurobiol. Dis. (2000). doi:10.1006/nbdi.1999.0279 
14. Muratore, C. R. et al. The familial alzheimer's disease APPV717I mutation alters APP processing and Tau expression in iPSC-derived neurons. Hum. Mol. Genet. (2014). doi:10.1093/hmg/ddu064

15. Verheyen, A. et al. Using human iPSC-derived neurons to model TAU aggregation. PLoS One (2015). doi:10.1371/journal.pone.0146127

16. Silva, M. C. et al. Human iPSC-Derived Neuronal Model of Tau-A152T Frontotemporal Dementia Reveals Tau-Mediated Mechanisms of Neuronal Vulnerability. Stem Cell Reports (2016). doi:10.1016/j.stemcr.2016.08.001

17. Wang, C. et al. Scalable Production of iPSC-Derived Human Neurons to Identify Tau-Lowering Compounds by High-Content Screening. Stem Cell Reports (2017). doi:10.1016/j.stemcr.2017.08.019

18. Sohn, P. D. et al. Pathogenic Tau Impairs Axon Initial Segment Plasticity and Excitability Homeostasis. Neuron (2019). doi:10.1016/j.neuron.2019.08.008

19. Hu, B. Y. et al. Neural differentiation of human induced pluripotent stem cells follows developmental principles but with variable potency. Proc. Natl. Acad. Sci. U. S. A. (2010). doi:10.1073/pnas.0910012107

20. Gunhanlar, N. et al. A simplified protocol for differentiation of electrophysiologically mature neuronal networks from human induced pluripotent stem cells. Mol. Psychiatry (2017). doi:10.1038/mp.2017.56

21. Lin, H.-C. et al. D R A F T Ngn2 induces diverse neuronal lineages from human pluripotency. bioRxiv (2020).

22. Biedler, J. L. \& Schachner, M. Multiple Neurotransmitter Synthesis by Human Neuroblastoma Cell Lines and Clones. Cancer Res. (1978).

23. Kovalevich, J. \& Langford, D. Considerations for the use of SH-SY5Y neuroblastoma cells in neurobiology. Methods Mol. Biol. (2013). doi:10.1007/9781-62703-640-5_2

24. Encinas, M. et al. Sequential treatment of SH-SY5Y cells with retinoic acid and brain-derived neurotrophic factor gives rise to fully differentiated, neurotrophic factor-dependent, human neuron-like cells. J. Neurochem. (2000). doi:10.1046/j.1471-4159.2000.0750991.x

25. Bell, M. \& Zempel, H. Axonal TAU sorting in SH-SY5Y-derived neurons requires the C-terminus of TAU but is independent of Ankyrin G. bioRxiv 2020.06.26.173526 (2020).

26. Jahn, K. et al. A cell culture model for investigation of synapse influenceability: epigenetics, expression and function of gene targets important for synapse formation and preservation in SH-SY5Y neuroblastoma cells differentiated by retinoic acid. J. Neural Transm. 124, 1341-1367 (2017).

27. Rasband, M. N. The axon initial segment and the maintenance of neuronal polarity. Nature Reviews Neuroscience (2010). doi:10.1038/nrn2852 
28. Leterrier, C. The Axon Initial Segment, 50 Years Later: A Nexus for Neuronal Organization and Function. Curr. Top. Membr. (2016).

doi:10.1016/bs.ctm.2015.10.005

29. Paik, S., Somvanshi, R. K. \& Kumar, U. Somatostatin-Mediated Changes in Microtubule-Associated Proteins and Retinoic Acid-Induced Neurite Outgrowth in SH-SY5Y Cells. J. Mol. Neurosci. 120-134 (2019). doi:10.1007/s12031-01901291-2

30. Påhlman, S., Ruusala, A. I., Abrahamsson, L., Mattsson, M. E. K. \& Esscher, T. Retinoic acid-induced differentiation of cultured human neuroblastoma cells: a comparison with phorbolester-induced differentiation. Cell Differ. (1984). doi:10.1016/0045-6039(84)90038-1

31. Gimenez-Cassina, A., Lim, F. \& Diaz-Nido, J. Differentiation of a human neuroblastoma into neuron-like cells increases their susceptibility to transduction by herpesviral vectors. J. Neurosci. Res. (2006). doi:10.1002/jnr.20976

32. Cheung, Y. T. et al. Effects of all-trans-retinoic acid on human SH-SY5Y neuroblastoma as in vitro model in neurotoxicity research. Neurotoxicology (2009). doi:10.1016/j.neuro.2008.11.001

33. Agholme, L., Lindström, T., Kgedal, K., Marcusson, J. \& Hallbeck, M. An in vitro model for neuroscience: Differentiation of SH-SY5Y cells into cells with morphological and biochemical characteristics of mature neurons. J. Alzheimer's Dis. (2010). doi:10.3233/JAD-2010-091363

34. Lopes, F. M. et al. Comparison between proliferative and neuron-like SH-SY5Y cells as an in vitro model for Parkinson disease studies. Brain Res. (2010). doi:10.1016/j.brainres.2010.03.102

35. Xie, H. R., Hu, L. Sen \& Li, G. Y. SH-SY5Y human neuroblastoma cell line: In vitro cell model of dopaminergic neurons in Parkinson's disease. Chinese Medical Journal (2010). doi:10.3760/cma.j.issn.0366-6999.2010.08.021

36. Shipley, M. M., Mangold, C. A. \& Szpara, M. L. Differentiation of the SH-SY5Y human neuroblastoma cell line. J. Vis. Exp. (2016). doi:10.3791/53193

37. Johansson, S. Graded action potentials generated by differentiated human neuroblastoma cells. Acta Physiol. Scand. 151, 331-341 (1994).

38. Tosetti, P., Taglietti, V. \& Toselli, M. Functional changes in potassium conductances of the human neuroblastoma cell line SH-SY5Y during in vitro differentiation. J. Neurophysiol. 79, 648-658 (1998).

39. Park, J. H. et al. High expression of large-conductance $\mathrm{Ca} 2+-$ activated $\mathrm{K}+$ channel in the CD133+ subpopulation of SH-SY5Y neuroblastoma cells. Biochem. Biophys. Res. Commun. 396, 637-642 (2010).

40. Hill, A. J. et al. Voltage-gated sodium ( $\mathrm{NaV}$ ) channel blockade by plant cannabinoids does not confer anticonvulsant effects per se. Neurosci. Lett. 566, 
269-274 (2014).

41. Sun, J. F. et al. Fenamates Inhibit Human Sodium Channel Nav1.2 and Protect Glutamate-Induced Injury in SH-SY5Y Cells. Cell. Mol. Neurobiol. 40, 1405-1416 (2020).

42. Sarkanen, J. R. et al. Cholesterol supports the retinoic acid-induced synaptic vesicle formation in differentiating human SH-SY5Y neuroblastoma cells. $J$. Neurochem. 102, 1941-1952 (2007).

43. Uberti, D., Rizzini, C., Spano, P. F. \& Memo, M. Characterization of tau proteins in human neuroblastoma SH-SY5Y cell line. Neurosci. Lett. (1997).

doi:10.1016/S0304-3940(97)00715-5

44. Smith, C. J., Anderton, B. H., Davis, D. R. \& Gallo, J. M. Tau isoform expression and phosphorylation state during differentiation of cultured neuronal cells. FEBS Lett. (1995). doi:10.1016/0014-5793(95)01221-Y

45. Goedert, M., Crowther, R. A. \& Garner, C. C. Molecular characterization of microtubule-associated proteins tau and map2. Trends in Neurosciences (1991). doi:10.1016/0166-2236(91)90105-4

46. Xia, D., Gutmann, J. M. \& Gotz, J. Mobility and subcellular localization of endogenous, gene-edited Tau differs from that of over-expressed human wild-type and P301L mutant Tau. Sci. Rep. (2016). doi:10.1038/srep29074

47. Bachmann, S., Bell, M., Klimek, J. \& Zempel, H. Subcellular localization of TAU isoforms and their influence on microtubule dynamics. bioRxiv 2020.06.16.154757 (2020). doi:10.1101/2020.06.16.154757

48. Leterrier, C. The axon initial segment: An updated viewpoint. J. Neurosci. (2018). doi:10.1523/JNEUROSCI.1922-17.2018

49. Van Beuningen, S. F. B. et al. TRIM46 Controls Neuronal Polarity and Axon Specification by Driving the Formation of Parallel Microtubule Arrays. Neuron (2015). doi:10.1016/j.neuron.2015.11.012

50. Kneynsberg, A., Vega, I. \& Kanaan, N. M. TRIM46 Knockdown Causes Neuronal Tau Redistribution and Increases Axosomatic Tau Diffusion. Alzheimer's Dement. (2019). doi:10.1016/j.jalz.2019.06.4852

51. Goedert, M., Spillantini, M. G., Jakes, R., Rutherford, D. \& Crowther, R. A. Multiple isoforms of human microtubule-associated protein tau: sequences and localization in neurofibrillary tangles of Alzheimer's disease. Neuron (1989). doi:10.1016/08966273(89)90210-9

52. Cleveland, D. W., Hwo, S. Y. \& Kirschner, M. W. Purification of tau, a microtubuleassociated protein that induces assembly of microtubules from purified tubulin. $J$. Mol. Biol. (1977). doi:10.1016/0022-2836(77)90213-3

53. Götz, J. et al. Somatodendritic localization and hyperphosphorylation of tau protein in transgenic mice expressing the longest human brain tau isoform. EMBO J. 
(1995). doi:10.1002/j.1460-2075.1995.tb07116.x

54. Goedert, M., Spillantini, M. G., Potier, M. C., Ulrich, J. \& Crowther, R. A. Cloning and sequencing of the cDNA encoding an isoform of microtubule-associated protein tau containing four tandem repeats: differential expression of tau protein mRNAs in human brain. EMBO J. (1989). doi:10.1002/j.14602075.1989.tb03390.x

55. Nunez, J. \& Fischer, I. Microtubule-Associated Proteins (MAPs) in the Peripheral Nervous System during Development and Regeneration. J. Mol. Neurosci. (1997). doi:10.1007/BF02736834

56. Couchie, D. et al. Primary structure of high molecular weight tau present in the peripheral nervous system. Proc. Natl. Acad. Sci. U. S. A. (1992). doi:10.1073/pnas.89.10.4378

57. Zempel, H. et al. Axodendritic sorting and pathological missorting of Tau are isoform-specific and determined by axon initial segment architecture. J. Biol. Chem. (2017). doi:10.1074/jbc.M117.784702

58. Dupont-Wallois, L. et al. Shift from fetal-type to Alzheimer-type phosphorylated Tau proteins in SKNSH-SY 5Y cells treated with okadaic acid. FEBS Lett. (1995). doi:10.1016/0014-5793(94)01361-4

59. Tanaka, T., Iqbal, K., Trenkner, E., Dong Jie Liu \& Grundke-lqbal, I. Abnormally phosphorylated tau in SY5Y human neuroblastoma cells. FEBS Lett. (1995). doi:10.1016/0014-5793(95)00061-D

60. Trabzuni, D. et al. MAPT expression and splicing is differentially regulated by brain region: Relation to genotype and implication for tauopathies. Hum. Mol. Genet. (2012). doi:10.1093/hmg/dds238

61. Goedert, M. \& Jakes, R. Expression of separate isoforms of human tau protein: correlation with the tau pattern in brain and effects on tubulin polymerization. EMBO J. (1990). doi:10.1002/j.1460-2075.1990.tb07870.x

62. Spillantini, M. G. \& Goedert, M. Tau protein pathology in neurodegenerative diseases. Trends in Neurosciences (1998). doi:10.1016/S0166-2236(98)01337-X

63. Hong, M. et al. Mutation-specific functional impairments in distinct tau isoforms of hereditary FTDP-17. Science (80-. ). (1998). doi:10.1126/science.282.5395.1914

64. Arendt, T., Stieler, J. T. \& Holzer, M. Tau and tauopathies. Brain Research Bulletin (2016). doi:10.1016/j.brainresbull.2016.08.018

65. Lee, M., McGeer, E. \& McGeer, P. L. Activated human microglia stimulate neuroblastoma cells to upregulate production of beta amyloid protein and tau: Implications for Alzheimer's disease pathogenesis. Neurobiol. Aging (2015). doi:10.1016/j.neurobiolaging.2014.07.024

66. Biernat, J., Gustke, N., Drewes, G., Mandelkow, E. \& Mandelkow, E. Phosphorylation of Ser262 strongly reduces binding of tau to microtubules: 
Distinction between PHF-like immunoreactivity and microtubule binding. Neuron (1993). doi:10.1016/0896-6273(93)90279-Z

67. Morris, M. et al. Tau post-translational modifications in wild-type and human amyloid precursor protein transgenic mice. Nat. Neurosci. (2015). doi:10.1038/nn.4067

68. Usardi, A. et al. Tyrosine phosphorylation of tau regulates its interactions with Fyn $\mathrm{SH} 2$ domains, but not $\mathrm{SH} 3$ domains, altering the cellular localization of tau. FEBS J. (2011). doi:10.1111/j.1742-4658.2011.08218.x

69. Reynolds, C. H. et al. Phosphorylation regulates tau interactions with Src homology 3 domains of phosphatidylinositol 3-kinase, phospholipase Cy1, Grb2, and Src family kinases. J. Biol. Chem. (2008). doi:10.1074/jbc.M709715200

70. Noble, W., Hanger, D. P., Miller, C. C. J. \& Lovestone, S. The importance of tau phosphorylation for neurodegenerative diseases. Frontiers in Neurology (2013). doi:10.3389/fneur.2013.00083

71. Kopke, E. et al. Microtubule-associated protein tau. Abnormal phosphorylation of a non- paired helical filament pool in Alzheimer disease. J. Biol. Chem. (1993).

72. Zheng-Fischhöfer, Q. et al. Sequential phosphorylation of Tau by glycogen synthase kinase-3 $\beta$ and protein kinase A at Thr212 and Ser214 generates the Alzheimer-specific epitope of antibody AT100 and requires a paired-helicalfilament-like conformation. Eur. J. Biochem. (1998). doi:10.1046/j.14321327.1998.2520542.x

73. Alavi Naini, S. M. \& Soussi-Yanicostas, N. Tau Hyperphosphorylation and Oxidative Stress, a Critical Vicious Circle in Neurodegenerative Tauopathies? Oxidative Medicine and Cellular Longevity (2015). doi:10.1155/2015/151979

74. Šimić, G. et al. Tau protein hyperphosphorylation and aggregation in alzheimer's disease and other tauopathies, and possible neuroprotective strategies. Biomolecules (2016). doi:10.3390/biom6010006

75. Buée, L., Bussière, T., Buée-Scherrer, V., Delacourte, A. \& Hof, P. R. Tau protein isoforms, phosphorylation and role in neurodegenerative disorders. Brain Research Reviews (2000). doi:10.1016/S0165-0173(00)00019-9

76. Hasegawa, M. et al. Characterization of mAb AP422, a novel phosphorylationdependent monoclonal antibody against tau protein. FEBS Lett. (1996). doi:10.1016/0014-5793(96)00271-2

77. Majd, S., Koblar, S. \& Power, J. Compound C enhances tau phosphorylation at Serine396 via PI3K activation in an AMPK and rapamycin independent way in differentiated SH-SY5Y cells. Neurosci. Lett. (2018). doi:10.1016/j.neulet.2018.01.049

78. Tanaka, T., Zhong, J., Iqbal, K., Trenkner, E. \& Grundke-lqbal, I. The regulation of phosphorylation of $\mathrm{T}$ in SY5Y neuroblastoma cells: The role of protein 
phosphatases. FEBS Lett. (1998). doi:10.1016/S0014-5793(98)00346-9

79. Boban, M., Babić Leko, M., Miškić, T., Hof, P. R. \& Šimić, G. Human neuroblastoma SH-SY5Y cells treated with okadaic acid express phosphorylated high molecular weight tau-immunoreactive protein species. J. Neurosci. Methods (2019). doi:10.1016/j.jneumeth.2018.09.030

80. Sayas, C. L., Moreno-Flores, M. T., Avila, J. \& Wandosell, F. The neurite retraction induced by lysophosphatidic acid increases Alzheimer's disease-like Tau phosphorylation. J. Biol. Chem. (1999). doi:10.1074/jbc.274.52.37046

81. Hernandez, P., Lee, G., Sjoberg, M. \& MacCioni, R. B. Tau phosphorylation by cdk5 and Fyn in response to amyloid peptide A $325-35$ : Involvement of lipid rafts. J. Alzheimer's Dis. (2009). doi:10.3233/JAD-2009-0933

82. Majd, S., Majd, Z., Koblar, S. \& Power, J. Beta estradiol and norepinephrine treatment of differentiated $\mathrm{SH}-\mathrm{SY} 5 \mathrm{Y}$ cells enhances tau phosphorylation at (Ser396) and (Ser262) via AMPK but not mTOR signaling pathway. Mol. Cell. Neurosci. (2018). doi:10.1016/j.mcn.2018.02.004

83. Wang, H. Bin, Li, T., Ma, D. Z. \& Zhi, H. ERa36 gene silencing promotes tau protein phosphorylation, inhibits cell proliferation, and induces apoptosis in human neuroblastoma SH-SY5Y cells. FASEB J. (2018). doi:10.1096/fj.201701386

84. Chan, E. W. L., Krishnansamy, S., Wong, C. \& Gan, S. Y. The NLRP3 inflammasome is involved in the neuroprotective mechanism of neural stem cells against microglia-mediated toxicity in SH-SY5Y cells via the attenuation of tau hyperphosphorylation and amyloidogenesis. Neurotoxicology (2019). doi:10.1016/j.neuro.2018.11.001

85. Yeo, E. T. Y. et al. Piper sarmentosum Roxb. confers neuroprotection on betaamyloid $(A \beta)$-induced microglia-mediated neuroinflammation and attenuates tau hyperphosphorylation in SH-SY5Y cells. J. Ethnopharmacol. (2018). doi:10.1016/j.jep.2018.02.025

86. Chen, I. C. et al. Formulated Chinese medicine shaoyao gancao tang reduces tau aggregation and exerts neuroprotection through anti-oxidation and antiinflammation. Oxid. Med. Cell. Longev. (2018). doi:10.1155/2018/9595741

87. Nie, S. D. et al. High glucose forces a positive feedback loop connecting ErbB4 expression and mTOR/S6K pathway to aggravate the formation of tau hyperphosphorylation in differentiated SH-SY5Y cells. Neurobiol. Aging (2018). doi:10.1016/j.neurobiolaging.2018.03.023

88. Chen, L. et al. Methamphetamine exposure upregulates the amyloid precursor protein and hyperphosphorylated tau expression: The roles of insulin signaling in sh-sy5y cell line. J. Toxicol. Sci. (2019). doi:10.2131/jts.44.493

89. Olivera-Santa Catalina, M. et al. Hyperosmotic Stress Induces Tau Proteolysis by Caspase-3 Activation in SH-SY5Y Cells. J. Cell. Biochem. (2016). doi:10.1002/jcb.25579 
90. Olivera Santa-Catalina, M. et al. JNK signaling pathway regulates sorbitol-induced Tau proteolysis and apoptosis in SH-SY5Y cells by targeting caspase-3. Arch. Biochem. Biophys. (2017). doi:10.1016/j.abb.2017.11.004

91. Liu, Z., Wang, F., Tang, M., Zhao, Y. \& Wang, X. Amyloid $\beta$ and tau are involved in sleep disorder in Alzheimer's disease by orexin $A$ and adenosine $A(1)$ receptor. Int. J. Mol. Med. (2019). doi:10.3892/ijmm.2018.3935

92. Zempel, H. \& Mandelkow, E. M. Tracking Tau in neurons: How to grow, fix, and stain primary neurons for the investigation of Tau in all developmental stages. in Methods in Molecular Biology (2017). doi:10.1007/978-1-4939-6598-4_20

93. Delobel, P. et al. Stable-Tau Overexpression in Human Neuroblastoma Cells: An Open Door for Explaining Neuronal Death in Tauopathies. in Annals of the New York Academy of Sciences (2003). doi:10.1196/annals.1299.115

94. Mailliot, C. et al. Pathological Tau Phenotypes: The Weight of Mutations, Polymorphisms, and Differential Neuronal Vulnerabilities. Ann. N. Y. Acad. Sci. (2006). doi:10.1111/j.1749-6632.2000.tb06911.x

95. Lee, V. M.-Y., Goedert, M. \& Trojanowski, J. Q. Neurodegenerative Tauopathies. Annu. Rev. Neurosci. (2001). doi:10.1146/annurev.neuro.24.1.1121

96. David, D. C. et al. Proteasomal degradation of tau protein. J. Neurochem. (2002). doi:10.1046/j.1471-4159.2002.01137.x

97. Luo, M. H., Tse, S. W., Memmott, J. \& Andreadis, A. Novel isoforms of tau that lack the microtubule-binding domain. J. Neurochem. (2004). doi:10.1111/j.14714159.2004.02508.x

98. Chang, K. H. et al. The aqueous extract of Glycyrrhiza inflata can upregulate unfolded protein response-mediated chaperones to reduce tau misfolding in cell models of Alzheimer's disease. Drug Des. Devel. Ther. (2016). doi:10.2147/DDDT.S96454

99. Kim, H. et al. CRISPR-Cas9 mediated telomere removal leads to mitochondrial stress and protein aggregation. Int. J. Mol. Sci. (2017). doi:10.3390/ijms18102093

100. Bao, L. et al. Depletion of the human ion channel TRPM2 in neuroblastoma demonstrates its key role in cell survival through modulation of mitochondrial reactive oxygen species and bioenergetics. J. Biol. Chem. (2016). doi:10.1074/jbc.M116.747147

101. Kim, S. et al. GBA1 deficiency negatively affects physiological $\alpha$-synuclein tetramers and related multimers. Proc. Natl. Acad. Sci. U. S. A. (2018). doi:10.1073/pnas.1700465115

102. Xu, Y., Gao, Y. W. \& Yang, Y. SC79 protects dopaminergic neurons from oxidative stress. Oncotarget (2018). doi:10.18632/oncotarget.23538

103. Prasuhn, J., Mårtensson, C. U., Krajka, V., Klein, C. \& Rakovic, A. Genomeedited, TH-expressing neuroblastoma cells as a disease model for dopamine- 
related disorders: A proof-of-concept study on DJ-1-deficient parkinsonism. Front. Cell. Neurosci. (2018). doi:10.3389/fncel.2017.00426

104. Rees, H. A. \& Liu, D. R. Base editing: precision chemistry on the genome and transcriptome of living cells. Nature Reviews Genetics (2018). doi:10.1038/s41576-018-0059-1

105. Anzalone, A. V. et al. Search-and-replace genome editing without double-strand breaks or donor DNA. Nature (2019). doi:10.1038/s41586-019-1711-4

106. Ambros, P. F. et al. International consensus for neuroblastoma molecular diagnostics: Report from the International Neuroblastoma Risk Group (INRG) Biology Committee. British Journal of Cancer (2009). doi:10.1038/sj.bjc.6605014

107. George, R. E. et al. Genome-wide analysis of neuroblastomas using high-density single nucleotide polymorphism arrays. PLoS One (2007). doi:10.1371/journal.pone.0000255

108. Stallings, R. L. Origin and functional significance of large-scale chromosomal imbalances in neuroblastoma. Cytogenetic and Genome Research (2007). doi:10.1159/000108291

109. Schleiermacher, G. et al. Accumulation of segmental alterations determines progression in neuroblastoma. J. Clin. Oncol. (2010). doi:10.1200/JCO.2009.26.7955

110. Schleiermacher, G. et al. Segmental chromosomal alterations lead to a higher risk of relapse in infants with MYCN-non-amplified localised unresectable/disseminated neuroblastoma (a SIOPEN collaborative study). Br. J. Cancer (2011). doi:10.1038/bjc.2011.472

111. Yusuf, M., Leung, K., Morris, K. J. \& Volpi, E. V. Comprehensive cytogenomic profile of the in vitro neuronal model SH-SY5Y. Neurogenetics (2013). doi:10.1007/s10048-012-0350-9

112. Spengler, B. A., Biedler, J. L. \& Ross, R. A. A corrected karyotype for the SHSY5Y human neuroblastoma cell line. Cancer Genetics and Cytogenetics (2002). doi:10.1016/S0165-4608(02)00523-X

113. Kryh, H. et al. Comprehensive SNP array study of frequently used neuroblastoma cell lines; copy neutral loss of heterozygosity is common in the cell lines but uncommon in primary tumors. BMC Genomics (2011). doi:10.1186/1471-2164-12443

114. Cohen, N., Betts, D. R., Rechavi, G., Amariglio, N. \& Trakhtenbrot, L. Clonal expansion and not cell interconversion is the basis for the neuroblast and nonneuronal types of the SK-N-SH neuroblastoma cell line. Cancer Genet. Cytogenet. (2003). doi:10.1016/S0165-4608(02)00835-X

115. Do, J. H., Kim, I. S., Park, T. K. \& Choi, D. K. Genome-wide examination of chromosomal aberrations in neuroblastoma SH-SY5Y cells by array-based 
comparative genomic hybridization. Mol. Cells (2007).

116. Sola, M. et al. Tau affects P53 function and cell fate during the DNA damage response. Nat. Commun. Biol. 3, 245 (2020).

117. Braak, H. \& Braak, E. Neuropathological stageing of Alzheimer-related changes. Acta Neuropathologica (1991). doi:10.1007/BF00308809

118. Braak, H. \& Del Tredici, K. The pathological process underlying Alzheimer's disease in individuals under thirty. Acta Neuropathol. (2011). doi:10.1007/s00401010-0789-4

119. Dickson, D. W., Kouri, N., Murray, M. E. \& Josephs, K. A. Neuropathology of frontotemporal lobar degeneration-Tau (FTLD-Tau). in Journal of Molecular Neuroscience (2011). doi:10.1007/s12031-011-9589-0

120. Oyarce, A. M. \& Fleming, P. J. Multiple forms of human dopamine $\beta$-hydroxylase in SH-SY5Y neuroblastoma cells. Arch. Biochem. Biophys. (1991). doi:10.1016/0003-9861(91)90573-2

121. Cuende, J., Moreno, S., Bolaños, J. P. \& Almeida, A. Retinoic acid downregulates Rae1 leading to APCCdh1 activation and neuroblastoma SH-SY5Y differentiation. Oncogene (2008). doi:10.1038/sj.onc.1210987

122. Presgraves, S. P., Ahmed, T., Borwege, S. \& Joyce, J. N. Terminally differentiated SH-SY5Y cells provide a model system for studying neuroprotective effects of dopamine agonists. Neurotox. Res. (2003). doi:10.1007/BF03033178

123. Adem, A., Mattsson, M. E. K., Nordberg, A. \& Påhlman, S. Muscarinic receptors in human SH-SY5Y neuroblastoma cell line: regulation by phorbol ester and retinoic acid-induced differentiation. Dev. Brain Res. (1987). doi:10.1016/01653806(87)90156-8

124. Neuhaus, J. F. G. et al. Catecholamine metabolism drives generation of mitochondrial DNA deletions in dopaminergic neurons. Brain (2014). doi:10.1093/brain/awt291

125. de Medeiros, L. M. et al. Cholinergic Differentiation of Human Neuroblastoma SHSY5Y Cell Line and Its Potential Use as an In vitro Model for Alzheimer's Disease Studies. Mol. Neurobiol. (2019). doi:10.1007/s12035-019-1605-3

126. Påhlman, S., Odelstad, L., Larsson, E., Grotte, G. \& Nilsson, K. Phenotypic changes of human neuroblastoma cells in culture induced by 12 -O-tetradecanoylphorbol-13-acetate. Int. J. Cancer (1981). doi:10.1002/ijc.2910280509

127. Murphy, N. P., Ball, S. G. \& Vaughan, P. F. T. Potassium- and Carbachol-Evoked Release of [3H]Noradrenaline from Human Neuroblastoma Cells, SH-SY5Y. J. Neurochem. (1991). doi:10.1111/j.1471-4159.1991.tb02085.x

128. Scott, I. G., Åkerman, K. E. O., Heikkilä, J. E., Kaila, K. \& Andersson, L. C. Development of a neural phenotype in differentiating ganglion cell-derived human neuroblastoma cells. J. Cell. Physiol. (1986). doi:10.1002/jcp.1041280221 
129. Kume, T. et al. Dibutyryl cyclic AMP induces differentiation of human neuroblastoma SH-SY5Y cells into a noradrenergic phenotype. Neurosci. Lett. (2008). doi:10.1016/j.neulet.2008.07.079

130. Sánchez, S. et al. A cAMP-activated pathway, including PKA and PI3K, regulates neuronal differentiation. Neurochem. Int. (2004). doi:10.1016/S01970186(03)00150-5

131. Itano, Y., Ito, A., Uehara, T. \& Nomura, Y. Regulation of Bcl-2 Protein Expression in Human Neuroblastoma SH-SY5Y Cells: Positive and Negative Effects of Protein Kinases C and A, Respectively. J. Neurochem. (2002). doi:10.1046/j.14714159.1996.67010131.x

132. Simpson, P. B. et al. Retinoic acid-evoked differentiation of neuroblastoma cells predominates over growth factor stimulation: An automated image capture and quantitation approach to neuritogenesis. Anal. Biochem. (2001). doi:10.1006/abio.2001.5346

133. Lyness, S. A., Zarow, C. \& Chui, H. C. Neuron loss in key cholinergic and aminergic nuclei in Alzheimer disease: A meta-analysis. Neurobiology of Aging (2003). doi:10.1016/S0197-4580(02)00057-X

134. Mesulam, M., Shaw, P., Mash, D. \& Weintraub, S. Cholinergic nucleus basalis tauopathy emerges early in the aging-MCI-AD continuum. Ann. Neurol. (2004). doi:10.1002/ana.20100

135. Sassin, I. et al. Evolution of Alzheimer's disease-related cytoskeletal changes in the basal nucleus of Meynert. Acta Neuropathol. (2000).

doi:10.1007/s004019900178

136. Davies, P. \& Maloney, A. J. F. SELECTIVE LOSS OF CENTRAL CHOLINERGIC NEURONS IN ALZHEIMER'S DISEASE. The Lancet (1976). doi:10.1016/S01406736(76)91936-X

137. Bowen, D. M., Smith, C. B., White, P. \& Davison, A. N. Neurotransmitter-related enzymes and indices of hypoxia in senile dementia and other abiotrophies. Brain (1976). doi:10.1093/brain/99.3.459

138. Mufson, E. J. et al. Loss of nucleus basalis neurons containing trkA immunoreactivity in individuals with mild cognitive impairment and early Alzheimer's diseases. J. Comp. Neurol. (2000). doi:10.1002/10969861(20001106)427:1<19::AID-CNE2>3.0.CO;2-A

139. Mufson, E. J. et al. Loss of basal forebrain p75NTR immunoreactivity in subjects with mild cognitive impairment and Alzheimer's disease. J. Comp. Neurol. (2002). doi:10.1002/cne.10122

140. Gibb, W. R. G., Mountjoy, C. Q., Mann, D. M. A. \& Lees, A. J. The substantia nigra and ventral tegmental area in Alzheimer's disease and Down's syndrome. J. Neurol. Neurosurg. Psychiatry (1989). doi:10.1136/jnnp.52.2.193 
141. Burns, J. M., Galvin, J. E., Roe, C. M., Morris, J. C. \& McKeel, D. W. The pathology of the substantia nigra in Alzheimer disease with extrapyramidal signs. Neurology (2005). doi:10.1212/01.WNL.0000158423.05224.7F

142. Tabaton, M., Schenone, A., Romagnoli, P. \& Mancardi, G. L. A quantitative and ultrastructural study of substantia nigra and nucleus centralis superior in Alzheimer's disease. Acta Neuropathol. (1985). doi:10.1007/BF00690198

143. Storga, D., Vrecko, K., Birkmayer, J. G. D. \& Reibnegger, G. Monoaminergic neurotransmitters, their precursors and metabolites in brains of Alzheimer patients. Neurosci. Lett. (1996). doi:10.1016/0304-3940(95)12256-7

144. Ditter, S. M. \& Mirra, S. S. Neuropathologic and clinical features of Parkinson's disease in Alzheimer's disease patients. Neurology (1987). doi:10.1212/wnl.37.5.754

145. Forstl, H., Levy, R., Burns, A., Luthert, P. \& Cairns, N. Disproportionate loss of noradrenergic and cholinergic neurons as cause of depression in Alzheimer's disease - A hypothesis. Pharmacopsychiatry (1994). doi:10.1055/s-2007-1014267

146. Spillantini, M. G., Bird, T. D. \& Ghetti, B. Frontotemporal Dementia and Parkinsonism Linked to Chromosome 17: A New Group of Tauopathies. Brain Pathol. (2006). doi:10.1111/j.1750-3639.1998.tb00162.x

147. Spillantini, M. G. et al. Familial multiple system tauopathy with presenile dementia: A disease with abundant neuronal and glial tau filaments. Proc. Natl. Acad. Sci. U. S. A. (1997). doi:10.1073/pnas.94.8.4113

148. Baker, K. G., Törk, I., Hornung, J. P. \& Halasz, P. The human locus coeruleus complex: an immunohistochemical and three dimensional reconstruction study. Exp. Brain Res. (1989). doi:10.1007/BF00274983

149. German, D. C. et al. Disease-specific patterns of locus coeruleus cell loss. Ann. Neurol. (1992). doi:10.1002/ana.410320510

150. Busch, C., Bohl, J. \& Ohm, T. G. Spatial, temporal and numeric analysis of Alzheimer changes in the nucleus coeruleus. Neurobiol. Aging (1997). doi:10.1016/S0197-4580(97)00035-3

151. Braak, H. \& Del Tredici, K. Alzheimer's disease: Intraneuronal alterations precede insoluble amyloid- $\beta$ formation. Neurobiology of Aging (2004). doi:10.1016/j.neurobiolaging.2003.12.015

152. Aston-Jones, G. \& Cohen, J. D. AN INTEGRATIVE THEORY OF LOCUS COERULEUS-NOREPINEPHRINE FUNCTION: Adaptive Gain and Optimal Performance. Annu. Rev. Neurosci. (2005). doi:10.1146/annurev.neuro.28.061604.135709

153. Grudzien, A. et al. Locus coeruleus neurofibrillary degeneration in aging, mild cognitive impairment and early Alzheimer's disease. Neurobiol. Aging (2007). doi:10.1016/j.neurobiolaging.2006.02.007 
154. Satoh, A. \& lijima, K. M. Roles of tau pathology in the locus coeruleus (LC) in ageassociated pathophysiology and Alzheimer's disease pathogenesis: Potential strategies to protect the LC against aging. Brain Research (2019). doi:10.1016/j.brainres.2017.12.027

155. West, M. J., Coleman, P. D., Flood, D. G. \& Troncoso, J. C. Differences in the pattern of hippocampal neuronal loss in normal ageing and Alzheimer's disease. Lancet (1994). doi:10.1016/S0140-6736(94)92338-8

156. Tarantini, S., Tran, C. H. T., Gordon, G. R., Ungvari, Z. \& Csiszar, A. Impaired neurovascular coupling in aging and Alzheimer's disease: Contribution of astrocyte dysfunction and endothelial impairment to cognitive decline. Experimental Gerontology (2017). doi:10.1016/j.exger.2016.11.004

157. Lindemer, E. R., Greve, D. N., Fischl, B. R., Augustinack, J. C. \& Salat, D. H. Regional staging of white matter signal abnormalities in aging and Alzheimer's disease. Neurolmage Clin. (2017). doi:10.1016/j.nicl.2017.01.022

158. Fjell, A. M., McEvoy, L., Holland, D., Dale, A. M. \& Walhovd, K. B. What is normal in normal aging? Effects of aging, amyloid and Alzheimer's disease on the cerebral cortex and the hippocampus. Progress in Neurobiology (2014). doi:10.1016/j.pneurobio.2014.02.004

159. Braak, H. \& Braak, E. Development of Alzheimer-related neurofibrillary changes in the neocortex inversely recapitulates cortical myelogenesis. Acta Neuropathol. (1996). doi:10.1007/s004010050508

160. Braak, H., Rüb, U., Gai, W. P. \& Del Tredici, K. Idiopathic Parkinson's disease: Possible routes by which vulnerable neuronal types may be subject to neuroinvasion by an unknown pathogen. J. Neural Transm. (2003). doi:10.1007/s00702-002-0808-2

161. German, D. C., White, C. L. \& Sparkman, D. R. Alzheimer's disease: Neurofibrillary tangles in nuclei that project to the cerebral cortex. Neuroscience (1987). doi:10.1016/0306-4522(87)90123-0

162. Sanchez-Padilla, J. et al. Mitochondrial oxidant stress in locus coeruleus is regulated by activity and nitric oxide synthase. Nat. Neurosci. (2014). doi:10.1038/nn.3717

163. Åkerman, K. E. O., Scott, I. G. \& Andersson, L. C. Functional differentiation of a human ganglion cell derived neuroblastoma cell line SH-SY5Y induced by a phorbol ester (TPA). Neurochem. Int. (1984). doi:10.1016/0197-0186(84)90029-9

164. Brown, A. M., Riddoch, F. C., Robson, A., Redfern, C. P. F. \& Cheek, T. R. Mechanistic and functional changes in $\mathrm{Ca} 2+$ entry after retinoic acid-induced differentiation of neuroblastoma cells. Biochem. J. (2005). doi:10.1042/BJ20042127

165. Kisler, K., Nelson, A. R., Montagne, A. \& Zlokovic, B. V. Cerebral blood flow regulation and neurovascular dysfunction in Alzheimer disease. Nature Reviews 
Neuroscience (2017). doi:10.1038/nrn.2017.48

166. Pamphlett, R. Uptake of environmental toxicants by the locus ceruleus: A potential trigger for neurodegenerative, demyelinating and psychiatric disorders. Med. Hypotheses (2014). doi:10.1016/j.mehy.2013.11.016

167. Cohen, Z., Molinatti, G. \& Hamel, E. Astroglial and vascular interactions of noradrenaline terminals in the rat cerebral cortex. J. Cereb. Blood Flow Metab. (1997). doi:10.1097/00004647-199708000-00008

168. Rossor, M. N. Parkinson's disease and Alzheimer's disease as disorders of the isodendritic core. Br. Med. J. (Clin. Res. Ed). (1981).

doi:10.1136/bmj.283.6306.1588

169. Ramón-Moliner, E. \& Nauta, W. J. H. The isodendritic core of the brain stem. J. Comp. Neurol. (1966). doi:10.1002/cne.901260301 